ISSN: 2146-3042

DOI: $10.25095 /$ mufad.673722

\title{
Kurumsal Sürdürülebilirliğin Firmaların Finansal Performansına Etkisi: BIST Kurumsal Sürdürülebilirlik Endeksindeki Firmalar Üzerine Bir Araştırma*
}

\author{
Ahmet Furkan SAK ${ }^{* *}$ \\ Hüseyin DALGAR***
}

\section{$\ddot{O Z Z E T}$}

Kurumsal sürdürülebilirlik kavramı, Dünya Çevre ve Gelişme Komisyonu (WCED) tarafindan 1987 yılında yayımlanan Brundtland Raporu'yla birlikte tüm dünyada son derece önemli bir kavram haline gelmiştir. Geçmiş yıllarda ișletmeler sadece mal ve hizmet üretip satarken, günümüzde kurumsal sürdürülebilirlik uygulamalarına her geçen gün daha fazla önem veren sosyal ve ekonomik dönüşümün önderleri olarak sayılmaktadır. Bu çalışmanın amacı, işletmelerin kurumsal sürdürülebilirlik uygulamalarının finansal performanslarına bir etkisinin olup olmadığının ortaya konulmasıdır. Çalışmada 2013-2016 yıllarında BIST Kurumsal Sürdürülebilirlik Endeksi’nde yer alan banka dıșı 35 işletmenin 16 çeyrek döneme ait finansal bilgileri panel veri analizi yöntemi ile analiz edilmiştir. Modelde kullanılacak tahminci seçimine yönelik testler sonucunda model tahmincisi olarak Driscoll-Kraay dirençli tahmincisi belirlenmiştir. Analiz sonucunda, kurumsal sürdürülebilirlik uygulamalarının işletmelerin finansal performansına istatistiksel olarak anlamlı ve pozitif bir etkisinin olduğu bulunmuştur.

Anahtar Kelimeler: Sürdürülebilirlik, Kurumsal Sürdürülebilirlik, Finansal Performans, Panel Veri Analizi

JEL Sinıflandırması: L21, L25, Q56

The Effect Of Corporate Sustainability On Financial Performance Of Firms: A Research On The Firms In BIST Corporate Sustainability Index

\section{ABSTRACT}

The concept of corporate sustainability has become a remarkably significant concept throughout the World after the Brundtland Report published by the World Commission on Environment and Development (WCED) in 1987. While in the past, the businesses were only producing goods and services, nowadays, they are now perceived as the leaders of social and economic transition by placing more emphasis on corporate sustainability practices. The purpose of this study is to determine whether the corporate sustainability practices of firms affect their financial performances. In this study, publicly available financial information of 35 non-bank firm splaced in BIST Corporate Sustainability Index from 2013 to 2016 was analyzed with panel data analysis. After the tests to determine the model estimator, Driscoll-Kraay robustestimator was selected. As a result of the analysis, the existence of a positive and statistically significant effect of corporat esustainability on the financial performances of firms was founded.

Keywords: Sustainability, CorporateSustainability, Financial Performance, Panel Data Analysis

Jel Classification: L21, L25, Q56

* Bu makale Ahmet Furkan Sak'ın aynı başlıklı Yüksek Lisans tezinden üretilmiştir.

Makale Gönderim Tarihi: 21.03.2019, Makale Kabul Tarihi: 20.05.2019, Makale Türü: Araştırma Makalesi

** Arş. Gör.,Mehmet Akif Ersoy Üniversitesi, İktisadi ve İdari Bilimler Fakültesi, afsak@mehmetakif.edu.tr, Orcid ID: 0000-0002-6713-5773.

*** Prof. Dr., Mehmet Akif Ersoy Üniversitesi, İktisadi ve İdari Bilimler Fakültesi, hdalgar@mehmetakif.edu.tr, Orcid ID: 0000-0001-9743-3766. 


\section{GíRiş}

Modern hayatın bir sonucu olarak ortaya çıkan refahın istenmeyen unsurları olan fakirlik, gelir dağılımındaki eşitsizlik, çevresel ve teknolojik riskler, insan sağlı̆̆ına yönelik problemler ve doğal afetler dikkat çekici hasarlara sebep olmuştur. Bu sebeple gelişmenin sağlanması ve devam ettirilmesi adına artık yalnızca finansal konuların üzerinde durulması yeterli değildir. Gelişimin, sosyal ve çevresel boyutların da dikkate alınması ile sağlanması gerektiği düşüncesi güçlenmiştir. Konuların daha bütüncül, bağlantılı, adil, güvenilir, hesap verebilir ve şeffaf bir bakış açısıyla ele alınmasının önemi görülmeye başlanmıştır (Tokgöz ve Önce, 2009: 250).

$\mathrm{Bu}$ doğrultuda 1987 yılında yayınlanan Dünya Çevre ve Kalkınma Komisyonu (WCED) tarafindan yayımlanan Brundtland (Ortak Geleceğimiz) adlı rapor; çevre, kalkınma ve yönetişim konuları üzerinde daha fazla düşünülmesi gerektiği konusuna dikkat çekmiştir. 1992 yılında geçekleşen Uluslararası Çevre ve Kalkınma Konferansı'nda ise politikacılar, sivil toplum kuruluşları ve işadamları insanlığın yüzleştiği ekonomik büyüme, sosyal eşitlik ve çevrenin sürdürülebilirliğine yönelik sorunların birbirinden ayrı düşünülerek çözülemeyeceğini fark etmişlerdir. Hiçbir sağlıklı ekonominin ve toplumun, yoksulluk ve çevre kirliliğiyle dolu bir dünyada var olamayacağı düşüncesinden beslenen sürdürülebilir kalkınma kavramı giderek güç kazanmıştır (Nunesvd, 2010: 2).

Brundtland raporunda sürdürülebilir kalkınma "gelecek kuşakların kendi ihtiyaçlarını karşılama becerisini tehlikeye atmadan günümüz kuşağının ihtiyaçlarının karşılanması"şeklinde tanımlanmıştır. (WCED, 1987:37). Ancak, burada asıl önemli olan işletmelerin ve örgütlerin sürdürülebilir kalkınmaya nasıl katkı sağlayacağıdır. Tam da bu hususta kurumsal sürdürülebilirlik kavramı ortaya çıkmaktadır.

Ekonomi İşbirliği ve Kalkınma Örgütü (OrganisationforEconomicCo-operationand Development, OECD), Birleşmiş Milletler, G20 ve Dünya Borsalar Federasyonu'nun (WFE) da içinde yer aldığı birçok uluslararası kuruluş, istikrarlı ve uzun vadeli bir gelişmenin sağlanabilmesi için insan hakları ihlalleri, iklim değişikliği, doğal kaynakların tükenme noktasına gelmesi gibi gün geçtikçe şiddetini arttıran problemlerin en kısa zamanda çözüme kavuşturulması gerektiğinin farkına varmıştır. Bu sorunların çözüme ulaştırılmasının tek bir yolu vardır, o da işletmelerin sosyal, çevresel ve kurumsal yönetim alanlarındaki uygulamalarını, yani kısaca kurumsal sürdürülebilirlik faaliyetlerini arttırmasıdır (PWC, 2011: 3).

Çalışma kapsamında "Kurumsal sürdürülebilirliğin işletmelerin finansal performansına etkisi var midır?" sorusuna bir yanıt bulmak amaciyla, BIST Kurumsal Sürdürülebilirlik Endeksi'nde yer alan banka dışı 35 işletme üzerinde bir panel regresyon analizi yapılmıştır.

\section{LITERATÜR ARAŞTIRMASI}

Kurumsal sürdürülebilirlik ile finansal performans üzerine literatürde birçok çalışma mevcuttur. Çalışmamız ile benzerlik gösteren ulusal ve uluslararası çalışmalar aşağıda detaylı bir şekilde incelenmiştir. 
Lopez vd. (2007) 110 işletme üzerinde gerçekleştirdiği analizde işletmelerin Dow Jones Sürdürülebilirlik Endeksi'nde (Dow JonesSustainabilityIndex- DJSI) yer alıp almamasının vergi öncesi karına etki edip etmediğini çoklu doğrusal regresyon analizi yöntemini kullanarak araştırmışlardır. $\mathrm{Bu} 110$ işletmenin yarısı DJSI’te yer alan işletmeler iken, diğer yarısı benzer büyüklükte olup, DJSI'de işlem görmeyen işletmeden oluşmaktadır. Araştırma 1999-2001 ve 2002-2004 dönemleri için ayrı ayrı yapılmış, araştırma sonucunda 2002-2004 dönemi için işletmelerin DJSI'de olmasının işletme kârlılığına istatistiki olarak anlamlı ve pozitif bir etkisinin olduğu belirlenmiştir.

Lo ve Sheu (2007) yapmış oldukları çalışmada, 1999-2002 yılları arasında Amerika'da faaliyet gösteren, finansal olmayan 349 işletme üzerinde yaptığı analizde sürdürülebilirliğin işletme değerini etkisinin olup olmadığını incelemiştir. Yapılan çalışma sonucunda kurumsal sürdürülebilirlik ile Tobin'inq'su ile belirlenen işletme değeri arasında istatistiki olarak anlamlı ve pozitif bir ilişki olduğu ortaya konulmuştur.

Collison vd. (2008) yapmış oldukları çalışmada, Londra Menkul Kıymetler Borsası Sürdürülebilirlik Endeksi'nde (FTSE4Good) bulunan işletmeleri sosyal sorumluluk, yatırımcı ilişkileri, insan haklarına saygı, çevresel sürdürülebilirlik gibi sürdürülebilirlik endeks kriterleri yönünden değerlendirmişlerdir. Çalışma kapsamında işletmelerin sürdürülebilirlik endeksi öncesi ve sonrası performansları 1996 ile 2005 yılları baz alınarak incelenmiş ve yapılan analiz sonucunda işletmelerin sürdürülebilirlik endekine geçmesinin borsa performanslarını pozitif bir etkisinin bulunduğunu tespit edilmiştir.

Reddy ve Gordon (2010), Yeni Zelanda Borsası'na kayıtlı 17 ve Avustralya Borsası'na kayıtlı 51 işletmelerin gönüllü olarak yayımladıkları sürdürülebilirlik raporlarındaki verileri kullanarak oluşturdukları sürdürülebilirlik notları ile işletmelerin kârlılığ 1 arasındaki ilişkiyi incelemişlerdir. Analiz sonucunda işletmelerin kârlılığ ile kurumsal sürdürülebilirlikleri arasında istatistiki olarak anlamlı ve pozitif bir ilişkinin olduğu ortaya konmuştur.

Škare ve Golja (2012), 2006-2008 yılları arasını baz alarak yaptıkları çalışma kapsamında Dow Jones Dünya Sürdürülebilirlik Endeksi'ne kayıtll 45 işletme ile sürdürülebilirlik endeksine kayıtlı olmayan işletmeleri sürdürülebilir ve finansal performansları açısından karşılaştırmışlardır. Yapılan analiz sonucunda sürdürülebilirlik endeksine kayıtlı işletmelerin finansal performanslarının endekse giremeyen işletmelere göre yüksek olduğu belirlenmiştir.

Aggarwal (2013) 20 işletme üzerinde yapmış olduğu çalışmada, Hindistan'da işletmelerin kurumsal sürdürülebilirlik endeks notu ile farklı kârlılık oranları arasındaki ilişkiyi araştırmıştır. Yapılan analiz sonucunda, işletmelerin kurumsal sürdürülebilirlik endeks notu ile işletmelerin vergi öncesi karları arasında istatistiki olarak anlamlı ve pozitif bir ilişkinin varlığ 1 tespit edilmiştir.

Russo ve Mariani (2013) 2008-2011 yıllarını baz alarak yapmış oldukları çalışmada, Londra Menkul Kıymetler Borsası Sürdürülebilirlik Endeksi'nde (FTSE4Good) bulunmanın ve bu endeksten çıkarılmanın işletmenin kârlılığına olan etkisi incelemiştir. Yapılan analiz sonucunda, söz konusu sürdürülebilirlik endeksinden çıkarılmanın işletme kârlılığına olumsuz bir etkisinin olduğu sonucuna ulaşılmıştır. 
Charlo, Moya ve Muñoz (2015) yaptıkları çalışmada, İspanya Borsası'na kote olan işletmeleri sürdürülebilirlik endeksine kayıtlı olan, kayıtlı olmayan ve karışık olmak üzere 3 farklı gruba ayırmış ve bu grupları karşılaştırmıştır. Yapılan analiz sonucunda sürdürülebilirlik endeksinde yer alan işletmelerin, endekste yer almayan benzer risk düzeyindeki işletmelerden daha çok kâr elde ettikleri ve pazarda yaşanan değişimlere daha hızlı bir şekilde adapte olduklarını tespit edilmiştir.

Marti vd. (2015) yaptıkları çalışmada, Stoxx Europe 600 Endeksi ve Stoxx Europe Sürdürülebilirlik Endeksi'nde yer alan işletmeleri panel veri analizi kullanarak karşılaştırmışlardır. Yapılan analiz sonucunda 2007-2010 yılları arasında Sürdürülebilirlik Endeksi'nde bulunan işletmelerin Sürdürülebilirlik Endeksi'nde bulunmayan işletmelerden daha iyi finansal performans gösterdikleri ortaya konulmuştur.

Çıtak ve Ersoy (2016) yaptıkları çalışmada Borsa İstanbul (BIST) 30 Endeksi'nde bulunan 30 işletmeyi BIST Sürdürülebilirlik Endeksi'nde yer alan ve almayan 15'er işletme olarak iki gruba ayırmış, sürdürülebilirlik endeksinde yer alan ve almayan bu işletmelerin finansal performanslarında farklılaşma olup olmadığ BIST Sürdürülebilirlik Endeksi'nde yer alan işletmelerin Piyasa Değeri/Defter Değeri oranı ortalamasının sürdürülebilirlik endekinde yer almayan işletmelere göre istatistiki olarak anlamlı bir şekilde daha yüksek olduğu belirlenmiştir.

Wiengarten vd. (2017) 2004-2012 yılları arasında 123 işletmenin finansal verileri ile yapmış oldukları çalışmada işletmelerin yönetim kuruluna kurumsal sürdürülebilirlik yöneticisi atanmasının işletme kârlılığına etkisini araştırmıştır. Yapılan analiz sonucunda, işletmenin yönetim kuruluna kurumsal sürdürülebilirlik yöneticisinin atanmasının işletme kârlılığına istatistiksel olarak anlamlı ve pozitif bir etkisi olduğu ortaya konulmuştur.

Önder (2017) 91 işletme üzerinde 2016 yılı verilerinden yararlanarak yapmış olduğu çalışmada, çoklu doğrusal regresyon analizi ile BIST 100 endeksinde bulunan işletmelerin Sürdürülebilirlik Endeksi'nde yer almasının kârlılıkları üzerinde bir etkiye sahip olup olmadığ1 incelenmiştir. Yapılan analiz sonucunda kurumsal sürdürülebilirlik endeksine girmenin işletme kârlılığ

Altınay vd. (2017) 2014-2017 yılları arasında BIST Sürdürülebilirlik Endeksinde yer alan 4 bankanın sürdürülebilirlik endeksine kote olmadan önceki hisse senedi değerleri ile endekse kote olduktan sonraki hisse senedi değerlerini karşılaştırmıştır. Yapılan analiz sonucunda bankaların hisse senedi ortalamalarının endekse girmeden önce ve girdikten sonra herhangi bir değişim göstermediği sonucuna ulaşılmıştır.

\section{UYGULAMA}

\subsection{Veri Seti}

Çalışma kapsamında Borsa İstanbul Sürdürülebilirlik Endeksi’nde yer alan banka dışı 35 işletmenin 2013-2016 yılları arasındaki 16 çeyrek dönemdeki finansal tabloları kullanılmıştır. Çalışmada Borsa İstanbul Kurumsal Sürdürülebilirlik Endeksi'nde yer alan 7 bankaya yer verilmemiştir. Bunun sebebi bankaların sahip oldukları farklı yapısal özellikler 
nedeni ile finansal tabloların sunumunun banka dışı işletmelerden farklılaşmalarıdır. Araştırmaya dahil edilen 35 işletme aşağıdaki tabloda sunulmuştur.

Tablo 1. Araştırmaya Dahil Edilen İşletmeler

\begin{tabular}{|c|c|c|c|c|c|}
\hline $\begin{array}{l}\text { İşletme } \\
\text { No }\end{array}$ & $\begin{array}{l}\text { İşletme } \\
\text { Kodu }\end{array}$ & İşletme Adı & $\begin{array}{l}\text { İşletm } \\
\text { e No }\end{array}$ & $\begin{array}{l}\text { İşletme } \\
\text { Kodu }\end{array}$ & İşletme Adı \\
\hline 1 & ADEL & ADEL KALEMCİLIK & 19 & PGSUS & PEGASUS \\
\hline 2 & AKSEN & AKSA ENERJİ & 20 & PETKM & PETKIM \\
\hline 3 & AEFES & ANADOLU EFES & 21 & SAHOL & SABANCI HOLDING \\
\hline 4 & ARCLK & ARÇELİK & 22 & SISE & ŞIŞSE CAM \\
\hline 5 & ASELS & ASELSAN & 23 & TATGD & TAT GIDA \\
\hline 6 & BRISA & BRİSA & 24 & TAVHL & TAV HAVALIMANLARI \\
\hline 7 & CCOLA & COCA COLA İÇECEK & 25 & TKFEN & TEKFEN HOLDİNG \\
\hline 8 & DOHOL & DOĞAN HOLDİNG & 26 & TOASO & TOFAȘ OTO. FAB. \\
\hline 9 & DOAS & DOĞUŞ OTOMOTIV & 27 & TUPRS & TÜPRAŞ \\
\hline 10 & EREGL & EREĞLI DEMİR CELİK & 28 & THYAO & TÜRK HAVA YOLLARI \\
\hline 11 & FROTO & FORD OTOSAN & 29 & TTKOM & TÜRK TELEKOM \\
\hline 12 & GLYHO & GLOBAL YAT.HOLDİNG & 30 & TTRAK & TÜRK TRAKTÖR \\
\hline 13 & ISGYO & İŞ GMYO & 31 & TCELL & TURKCELL \\
\hline 14 & KCHOL & KOÇ HOLDİNG & 32 & ULKER & ÜLKER BİSKÜVİ \\
\hline 15 & KORDS & KORDSA GLOBAL & 33 & VESTL & VESTEL \\
\hline 16 & MGROS & MİGROS TİCARET & 34 & VESBE & VESTEL BEYAZ EŞYA \\
\hline 17 & NETAS & NETAŞ TELEKOM. & 35 & ZOREN & ZORLU ENERJI \\
\hline 18 & OTKAR & OTOKAR & & & \\
\hline
\end{tabular}

\subsection{Araştırma Modeli ve Tahminci Seçimi}

Araştırmada bağımlı değişken olarak literatürde yapılan birçok çalışmada finansal başarıyı ölçmede en başarılı yöntemlerden olan Varlık Kârlılı̆̆ının (Return of Asset- ROA) kullanılması tercih edilmiştir. Modelde yer verilen bağımsız değişkenlerin belirlenmesi sürecinde literatürde yer alan çalışmalar irdelenmiş ve finansal performans ile anlamlı bir etkisi bulunan değişkenler modele dâhil edilmiştir. Bu değişkenler şu şekildedir:

- $\quad$ ROA $_{\mathrm{it}}$ : İşletmelerin finansal performanslarını ölçmek için kullanılan ilk bağımlı değişken varlık kârlılığını ifade eden ROA'dır. Bu oran Net Kâr / Toplam Aktifler şeklinde hesaplanmaktadır.

- $\quad$ SÜRDÜRÜLEBİLİRLİK $\mathrm{it}_{\mathrm{it}}$ Bu değişken işletmelerin Borsa İstanbul Kurumsal Sürdürülebilirlik Endeksi (XUSRD)'ne girip girmeme durumlarına göre 0 ya da 1 değerlerini alan bir kukla değişkendir. Değerin 0 olması, işletmenin BIST XUSRD endeksine giremediğini, 1 olması ise endekse girebildiğini göstermektedir.

- $\quad$ KALDIRAÇit: İşletmelerin analize tabi tutulan dönemleri için hesaplanan Toplam Yükümlülükler / Toplam Aktifler oranıdır. Bir işletmedeki varlıkların ne kadarının borçlar ile finanse edildiğini gösteren değişkendir.

- $\quad$ CARİ $_{\text {it }}$ : İşletmelerin analize tabi tutulan dönemleri için hesaplanan Dönen Varlıklar / Kısa Vadeli Yükümlülükler oranıdır. İşletmelerin kısa vadeli borçlarını karşılama performansını analiz etmek için kullanılan ve likidite göstergesi olan bir değişkendir.

- $\quad$ BÜYÜME $E_{i t}$ : İşletmelerin analize tabi tutulan dönemleri için hesaplanan Toplam Varlıklar ${ }_{t}$ - Toplam Varlıklar Tol $_{1}$ ) Toplam Varlıklart-1 oranıdır. 
- $\quad$ RISKK $_{\text {it }}$ : İşletmelerin analize tabi tutulan yılları için incelenen işletme riskliliği, bir yıldaki 4 çeyrek dönemin faiz ve vergi öncesi karlarındaki (FAVÖK) standart sapması şeklinde hesaplanmıştır.

- $\quad \mathrm{ARGE}_{\text {it }}$ : İşletmelerin analize tabi tutulan yıllardaki çeyrek dönem itibariyle yaptıkları araştırma - geliştirme giderlerini ifade etmektedir.

- $\quad$ BÜYÜKLÜK $K_{i t}$ : İşletme büyüklüğünü ifade eden bu değişken işletmelerin çeyrek dönemler itibariyle yaptıkları satışların logaritmasının alınması ile bulunmuştur.

- $\quad$ LAGROA it: Bir önceki dönemin finansal başarısını ölçmek için kullanılan bu değişken, bir önceki çeyrek dönem varlık kârlılığını (ROA), LAGROA Net Kart-1 / Toplam Aktifler $t_{-I}$ şeklinde hesaplanmaktadır.

- $\quad$ BIST $_{\text {it }}$ : Bu değişken Borsa İstanbul 100 Endeksi'nin işletmelerin analize tabi tutulan yıllarındaki çeyrek dönemleri itibariyle en son aldığı değere bakılarak hesaplanmıştır.

- $\quad$ KARŞILAMA $A_{i t}$ : Bu değişken bir makro unsur olarak diş ticaret dengesini ifade etmekte olup, ihracatın ithalatı karşılama oranlarının 3'er aylık ortalaması alınarak hesaplanmıştır.

- $\quad \mathrm{USD}_{\text {it }}$ : İşletmelerin analize tabi tutulan yıllarındaki çeyrek dönemleri itibariyle incelenen bu değişken, T.C. Merkez Bankası USD satış kurunun 3'er aylık ortalaması alınarak hesaplanmıştır.

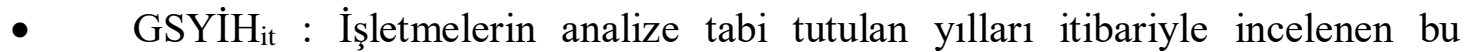
değişken, çeyrek dönemler itibariyle, çeyrek dönemin yer aldı̆̆ 1 yıldaki Türkiye'nin gayrisafi yurtiçi hasılası dikkate alınarak hesaplanmıştır.

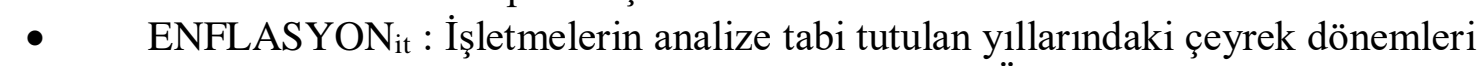
itibariyle incelenen bu değişken, tüketici fiyat endeksinin (TÜFE) 3'er aylık ortalaması alınarak hesaplanmıştır.

- $\quad \mathrm{FAİZ}_{\text {it }}$ : İşletmelerin analize tabi tutulan yıllarındaki çeyrek dönemleri itibariyle incelenen bu değişken, T.C. Merkez Bankası'nın gecelik faiz oranlarına bakılarak hesaplanmış, bir çeyrek dönemde birden fazla faiz oranının bulunması durumunda bu oranların ortalaması alınmıştır.

SÜRDÜRÜLEBİLİRLIKK kukla değişkeni ile çarpılması sonucu oluşan çapraz değişkenler de modele eklenmiştir. Bunun sebebi işletmelerin yalnızca kurumsal sürdürülebilirlik endeksine girdikleri dönemlerin dikkate alındığ 1 durumda, bu değişkenlerin finansal performansa bir etkisinin olup olmadığının belirlenmek istenmesidir. Bu çapraz değişkenler şu şekildedir:

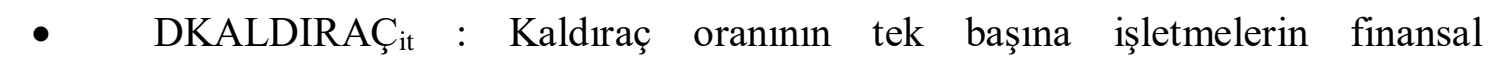
performansına etkisinin gözlemlenmesinin yanında, kurumsal sürdürülebilirlik ile birlikte finansal performansa bir etkisinin olup olmadığının ortaya konması için modele dahil edilen bu değişken, SÜRDÜRÜLEBİLİRLIKK X KALDIRAÇ şeklinde hesaplanmıştır.

- DCARİ $\dot{i}_{\text {it }}$ : Cari oranının tek başına işletmelerin finansal performansına etkisinin gözlemlenmesinin yanında, kurumsal sürdürülebilirlik ile birlikte finansal performansa bir etkisinin olup olmadığının ortaya konması için modele dahil edilen bu değişken, SÜRDÜRÜLEBİLİRLİK X CARİ şeklinde hesaplanmıştır.

- $\quad$ DBÜYÜME $E_{i t}$ : İşletmelerin büyüme oranının tek başına işletmelerin finansal performansına etkisinin gözlemlenmesinin yanında, kurumsal sürdürülebilirlik ile birlikte finansal performansa bir etkisinin olup olmadığının ortaya konması için modele dahil edilen bu değişken, SÜRDÜRÜLEBİLİRLIKK X BÜYÜME şeklinde hesaplanmıştır. 
- $\quad$ DRISSK $_{\text {it }}$ : İşletme riskliliğini tek başına işletmelerin finansal performansına etkisinin gözlemlenmesinin yanında, kurumsal sürdürülebilirlik ile birlikte finansal performansa bir etkisinin olup olmadığının ortaya konması için modele dahil edilen bu değişken, SÜRDÜRÜLEBILIIRLIK X RISSK șeklinde hesaplanmıştır.

- $\quad$ DARGE $_{i t}$ : İşletmelerin ARGE harcamalarının tek başına işletmelerin finansal performansına etkisinin gözlemlenmesinin yanında, kurumsal sürdürülebilirlik ile birlikte finansal performansa bir etkisinin olup olmadığının ortaya konması için modele dahil edilen bu değişken, SÜRDÜRÜLEBİLIRLIKK X ARGE şeklinde hesaplanmıştır.

DBÜYÜKLÜK $K_{\text {it }}$ : İşletme büyüklüğünün tek başına işletmelerin finansal performansına etkisinin gözlemlenmesinin yanında, kurumsal sürdürülebilirlik ile birlikte finansal performansa bir etkisinin olup olmadığının ortaya konması için modele dahil edilen bu değişken, SÜRDÜRÜLEBİLIRLIK X BÜYÜKLÜK şeklinde hesaplanmıştır.

- DLAGROA $A_{i t}$ : Bir önceki çeyrek dönem varlık karlılığının tek başına işletmelerin finansal performansına etkisinin gözlemlenmesinin yanında, kurumsal sürdürülebilirlik ile birlikte finansal performansa bir etkisinin olup olmadığının ortaya konması için modele dahil edilen bu değişken, SÜRDÜRÜLEBILIIRLİK X LAGROA şeklinde hesaplanmıştır.

- DBIST $_{\text {it }}$ : Borsa İstanbul 100 endeksinin tek başına işletmelerin finansal performansına etkisinin gözlemlenmesinin yanında, kurumsal sürdürülebilirlik ile birlikte finansal performansa bir etkisinin olup olmadığının ortaya konması için modele dahil edilen bu değişken, SÜRDÜRÜLEBİLİRLIK X BIST şeklinde hesaplanmıştır.

- DKARŞILAMA ${ }_{i t}$ : Diş ticaret dengesinin tek başına işletmelerin finansal performansına etkisinin gözlemlenmesinin yanında, kurumsal sürdürülebilirlik ile birlikte finansal performansa bir etkisinin olup olmadığının ortaya konması için modele dahil edilen bu değişken, SÜRDÜRÜLEBILİRLİK X KARŞILAMA şeklinde hesaplanmıştır.

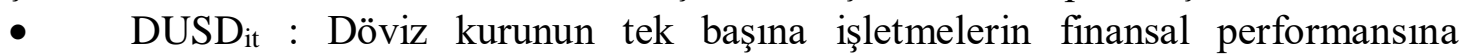
etkisinin gözlemlenmesinin yanında, kurumsal sürdürülebilirlik ile birlikte finansal performansa bir etkisinin olup olmadığının ortaya konması için modele dahil edilen bu değişken, SÜRDÜRÜLEBİLIRLIK X USD şeklinde hesaplanmıştır.

- DGSYIH ${ }_{i t}$ : Gayrisafi Yurtiçi Hasıla'nın tek başına işletmelerin finansal performansına etkisinin gözlemlenmesinin yanında, kurumsal sürdürülebilirlik ile birlikte finansal performansa bir etkisinin olup olmadığının ortaya konması için modele dahil edilen bu değişken, SÜRDÜRÜLEBİLİRLIK X GYSïH şeklinde hesaplanmıştır.

- DENFLASYON ${ }_{\mathrm{it}}$ : Enflasyon oranının tek başına işletmelerin finansal performansına etkisinin gözlemlenmesinin yanında, kurumsal sürdürülebilirlik ile birlikte finansal performansa bir etkisinin olup olmadığının ortaya konması için modele dahil edilen bu değişken, SÜRDÜRÜLEBILIIRLIK X ENFLASYON şeklinde hesaplanmıştır.

- DFAİZ ${ }_{i t}$ : Faiz oranlarının tek başına işletmelerin finansal performansına etkisinin gözlemlenmesinin yanında, kurumsal sürdürülebilirlik ile birlikte finansal performansa bir etkisinin olup olmadığının ortaya konması için modele dahil edilen bu değişken, SÜRDÜRÜLEBİLIRLIK X FAİZ şeklinde hesaplanmıştır.

Çalışmada kullanılan değişkenlerle ilgili özet, Tablo 2'de verilmiştir: 
Tablo 2. Çalışmada Kullanılan Değişkenlerle İlgili Özet Bilgiler

\begin{tabular}{|c|c|c|}
\hline DEĞISSKEN & AÇIKLAMA & SEMBOL \\
\hline Varlık Kârlılı̆̆ & Net Kâr / Toplam Varlıklar & ROA \\
\hline Kurumsal Sürdürülebilirlik & $\begin{array}{l}\text { BIST XUSRD Endeksine Girme }= \\
1, \text { Girmeme }=0\end{array}$ & SÜRDÜRÜLEBİLİRLİK \\
\hline Kaldıraç Oranı & $\begin{array}{l}\text { Toplam Yükümlülükler /Toplam } \\
\text { Aktifler }\end{array}$ & KALDIRAÇ \\
\hline Cari Oran & $\begin{array}{l}\text { Dönen Varlıklar / Kısa Vadeli } \\
\text { Yabancı Kaynaklar }\end{array}$ & CARI \\
\hline Varlıklarda Büyüme Oranı & $\begin{array}{l}\text { (Toplam Varlıklar }{ }^{-} \text {Toplam }^{-} \\
\left.\text {Varlıklar }_{t-1}\right) / \text { Toplam Varlıklart-1/ }\end{array}$ & BÜYÜME \\
\hline İşletme Riskliliği & $\begin{array}{l}\text { FAVÖK'teki Yıllık Değişimin } \\
\text { Standart Sapması }\end{array}$ & RİSK \\
\hline Araştırma - Geliştirme Harcamaları & & ARGE \\
\hline İșletme Büyüklüğü & Satışların Logaritması & BÜYÜKLÜK \\
\hline Bir Önceki Dönem Varlık Kârlılığ & Net Kâr ${ }_{t-1} /$ Toplam Varlıklar ${ }_{t-1}$ & LAGROA \\
\hline BIST 100 & BIST 100 Endeks Değeri & BIST \\
\hline İhracatın İthalatı Karşılama Oranı & 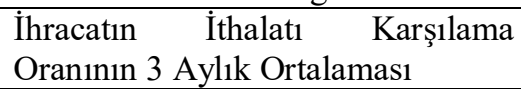 & KARŞILAMA \\
\hline USD Satış Fiyatı & $\begin{array}{l}\text { T.C. Merkez Bankası USD Satış } \\
\text { Fiyatı }\end{array}$ & USD \\
\hline GSYİH & Yıllık Gayrisafi Yurtiçi Hasıla & GSYİH \\
\hline TÜFE & $\begin{array}{lccc}\text { Tüketici } & \text { Fiyat Endeksi } & \text { Aylık } \\
\text { Değişim } & \text { Oranının } & 3 & \text { Aylık } \\
\text { Ortalaması } & & & \\
\end{array}$ & ENFLASYON \\
\hline Faiz Oran1 & T.C.M.B. Gecelik Faiz Oranı & FAİZ \\
\hline SÜRDÜRÜLEBILİRLIK*KALDIRAÇ & $\begin{array}{l}\text { Sürdürülebilirlik ile Kaldıraç Oranı } \\
\text { Çarpımı }\end{array}$ & DKALDIRAÇ \\
\hline SÜRDÜRÜLEBİLIRLIK*CARİ & $\begin{array}{l}\text { Sürdürülebilirlik ile Cari Oran } \\
\text { Çarpımı }\end{array}$ & DCARİ \\
\hline SÜRDÜRÜLEBİLİRLIK*BÜYÜME & $\begin{array}{l}\text { Sürdürülebilirlik ile } \\
\text { Büyümesi Oranı Çarpımı }\end{array}$ & DBÜYÜME \\
\hline SÜRDÜRÜLEBILLİRLIK*RİSK & $\begin{array}{l}\text { Sürdürülebilirlik ile işletme Riski } \\
\text { Carpımı }\end{array}$ & DRISK \\
\hline SÜRDÜRÜLEBILİRLIK*ARGE & $\begin{array}{l}\text { Sürdürülebilirlik ile } \\
\text { Harcamaları Çarpımı }\end{array}$ & DARGE \\
\hline SÜRDÜRÜLEBİLİRLIK*BÜYÜKLÜK & $\begin{array}{l}\text { Sürdürülebilirlik ile } \\
\text { Büyüklüğg̈ü Çarpımı }\end{array}$ & DBÜYÜKLÜK \\
\hline SÜRDÜRÜLEBILIIRLIK*LAGROA & $\begin{array}{l}\text { Sürdürülebilirlik ile } \quad \text { Geçmiş } \\
\text { Dönem Varlık kârlılığ } 1 \text { Çarpımı }\end{array}$ & DLAGROA \\
\hline SÜRDÜRÜLEBİLİRLİK*BIST & $\begin{array}{l}\text { Sürdürülebilirlik ile BIST } 100 \\
\text { Endeks Değeri Çarpımı }\end{array}$ & DBIST \\
\hline SÜRDÜRÜLEBILİRLIK*KARŞILAMA & $\begin{array}{l}\text { Sürdürülebilirlik ile İhracatın } \\
\text { İthalatı Karşılama Oranı Çarpımı }\end{array}$ & DKARŞILAMA \\
\hline SÜRDÜRÜLEBİLİRLIKK*USD & $\begin{array}{l}\text { Sürdürülebilirlik ile USD Satış } \\
\text { Fiyatı Çarpımı }\end{array}$ & DUSD \\
\hline SÜRDÜRÜLEBILIIRLIK*GSYİH & $\begin{array}{l}\text { Sürdürülebilirlik ile } \\
\text { Yurtiçi Hasılla Çarpımı } 1\end{array}$ & DGSYİH \\
\hline SÜRDÜRÜLEBİLİRLİK*ENFLASYON & Sürdürülebilirlik ile TÜFE çarpımı & DENFLASYON \\
\hline SÜRDÜRÜLEBİLIRLIK*FAİZ & $\begin{array}{l}\text { Sürdürülebilirlik ile Faiz Oranı } \\
\text { Çarpımı }\end{array}$ & DFAİZ \\
\hline
\end{tabular}

Araştırma değişkenlerine ait betimleyici istatistikler Tablo 3'de sunulmuştur. 
Tablo 3. Araştırma Değişkenlerine Ait Betimleyici İstatistikler

\begin{tabular}{|l|c|c|c|c|c|}
\hline \multicolumn{1}{|c|}{ Değişkenler } & $\begin{array}{c}\text { Gözlem } \\
\text { Sayısı }\end{array}$ & Ortalama & $\begin{array}{c}\text { Standart } \\
\text { Sapma }\end{array}$ & $\begin{array}{c}\text { MinimumD } \\
\text { eğer }\end{array}$ & $\begin{array}{c}\text { Maksimum } \\
\text { Değer }\end{array}$ \\
\hline ROA & 560 & 0.0305431 & 0.04459130 & -0.087474 & 0.3135456 \\
\hline KALDIRAÇ & 560 & 0.6194385 & 0.1677745 & 0.0928961 & 1.492872 \\
\hline CARİ & 560 & 1.506836 & 0.770973 & 0.2113308 & 5.073648 \\
\hline BÜYÜME & 560 & 1.053874 & 0.2259737 & 0.2054189 & 2.05580497 \\
\hline RíSK & 560 & 5.0868 & 14.89932 & 0.0860865 & 156.7337 \\
\hline SÜRDÜR. & 560 & 0.2982143 & 0.4578831 & 0 & 1 \\
\hline ARGE & 560 & $17,900,000$ & $40,600,000$ & 0 & $384,000,000$ \\
\hline BÜYÜKLÜK & 560 & 9.005625 & 0.5956145 & 6.95481 & 10.32288 \\
\hline BIST & 560 & $77,319.19$ & $5,147.065$ & 67,802 & 85,899 \\
\hline KARŞILAMA & 560 & 66.7801 & 4.907851 & 56.91804 & 74.05048 \\
\hline USD & 560 & 2.461346 & 0.4565927 & 1.786229 & 3.283866 \\
\hline GSYi் & 560 & 0.13548304 & 0.0142561 & 0.1153993 & 0.1529243 \\
\hline ENFLASYON & 560 & 0.663125 & 0.2816086 & 0.2266667 & 1.2 \\
\hline FAİZ & 560 & 9.828125 & 1.700482 & 6.75 & 12 \\
\hline
\end{tabular}

Tablo 3'e bakıldığında tüm değişkenler bazında 560 adet gözlem olduğu görülmektedir. Analizde yer alan her bir değiş̧ken tüm zamanlar boyunca gözlemlenmiş olduğu için (560), analizlerde kullanılan panel veri setinin dengeli panele örnek olduğu görülmektedir. Cari oran, işletme riskliliği ya da ARGE harcamaları gibi değişkenlerde minimum değer ile maksimum değer arasında büyük farkların bulunması ve standart sapmanın yüksek olması Kurumsal Sürdürülebilir Endeksi'nde yer alan işletmelerin farklı özelliklere sahip olduğunu göstermekte ve bu durum da işletmelerin farklı sektörlerde faaliyet göstermelerinden kaynaklanmaktadır.

Öncelikle araştırma kapsamında kullanılacak verilerin doğru modellenebilmesi adına F-Testi ile LM testleri uygulanmalıdır. Klasik modelin birim sabit etkiler modeline karşı test edilmesine yönelik F-Testinin yapılması gerekmektedir (Park,2011: 12). Bu test ile, $\left(\mathrm{H}_{0}\right.$ : $\mu_{\mathrm{i}}=0$ ) birim etkilerin tamamının sıfıra eşit olduğu yönündeki hipotez sınanmıştır. Ulaşılan $\mathrm{F}$ Testi istatistiği sonucu 3.30 'dur ve bu sonuç $\mathrm{F}$ dağılım tablosu ile $(\mathrm{F}(34,498)$ serbestlik derecesi ile) karşılaş̧ırıldığı zaman $\mathrm{H}_{0}$ birim etkilerin tamamının sıfıra eşit olduğu yönündeki hipotezi $\alpha=0.05$ 'de reddedilmektedir (Prob $>F=0.0000)$. Buna göre modelde birim sabit etkinin var olduğu ve bu nedenle klasik modelin kullanılamayacağı ortaya konulmuştur.

Birim sabit etkinin var olduğu sonucunun bulunmasından sonra, klasik modelin birim tesadüfi etkiler modeline karşı test edilmesi gerekmektedir (Tatoğlu, 2016: 176). Analizde, birim etkilerin toplamının sıfıra eşit olduğu hipotezi sınanmıştır. Elde edilen analiz sonucuna göre modelde birim tesadüfi etkilerin var olduğu ve bu nedenle klasik modelin kullanılamayacağı ortaya konulmuştur.

Modelde hem birim sabit etki, hem de birim tesadüfi etkinin varlı̆g 1 bulunduğu için, Hausman testine başvurulması gerekmektedir. Hausman testinde $\mathrm{H}_{0}$ hipotezinin reddedildiği durumda birim sabit etkiler modeli; $\mathrm{H}_{0}$ hipotezi reddedilmediği durumda ise birim tesadüfi etkiler modeli daha uygun bir model olacaktır (Park, 2011: 15-17). Hausman testi sonucunda analizde birim sabit etkiler modelinin uygulanmasını kararlaştırılmıştır. 
Buna göre araştırmada kullanılan tek yönlü birim sabit etkiler modeli şu şekildedir:

ROA $_{i t}=\alpha_{i}+\beta_{1}$ SÜRDÜRÜLEBİLİRLIK $_{i t}+\beta_{2}$ KALDIRAÇ $_{i t}+\beta_{3}$ CARİ $_{i t}+$ $\beta_{4}$ BÜYÜME $_{i t}+\beta_{5}$ RISSK $_{\text {it }}+\beta_{6}$ ARGE $_{i t}+\beta_{7}$ BÜYÜKLÜK $_{i t}+\beta_{8}$ LAGROA $_{i t}+\beta_{9}$ BIST $_{i t}+$ $\beta_{10}$ KARŞILAMA $_{i t}+\beta_{11}$ USD $_{\text {it }}+\beta_{12}$ GSYİH $_{\text {it }}+\beta_{13}$ ENFLASYON $_{i t}+\beta_{14}$ FAİZ $_{i t}+$ $\beta_{15}$ DKALDIRAÇit $+\quad \beta_{16}$ DCARI It $_{i t}+\quad \beta_{17}$ DBÜYÜME $_{i t}+\quad \beta_{18}$ DRISSK $_{i t}+\quad \beta_{19}$ DARGE $_{i t}+$ $\beta_{20}$ DBÜYÜKLÜK $K_{i t}+\quad \beta_{21}$ DLAGROA $_{i t}+\quad \beta_{22}$ DBIST $_{i t}+\quad \beta_{23}$ DKARŞILAMA $_{i t}+\quad \beta_{24}$ DUSD $_{i t}+$ $\beta_{25}$ DGSYİH $_{\mathrm{it}}+\beta_{26}$ DENFLASYON $_{\mathrm{it}}+\beta_{27} \mathrm{DFAIIZ}_{\mathrm{it}}+e_{\mathrm{it}}$

$$
\begin{aligned}
& i=1,2,3, \ldots .35 \\
& t=1,2,3, \ldots . .16
\end{aligned}
$$

Modellerde bulunan i'ler analiz kapsamındaki 35 işletmeye verilen 1'den 35'e kadar olan sayıları ifade etmekteyken; t'ler 2013'ün 1. çeyrek dönemi ile 2016'nın 4. çeyrek dönemi arasında yer alan 16 döneme verilen 1'den 16'ya kadar olan sayıları göstermektedir. $\alpha$ sabit terimi ifade etmekteyken; $\beta$ bağımsız değişkenlerin katsayılarını göstermektedir. $e$ ise işletmeler ve dönemler itibariyle karşılaşılan hata terimini ifade etmektedir.

Analizde kullanılacak modelin birim sabit etkiler modeli olduğunu tespit edilmesinden sonra, sabit etkiler tahmincisi olan Grup İçi Tahminci'nin (GİT) uygulanabilmesi adına homoskedasite, otokorelasyonsuzluk ve birimler arası korelasyonsuzlukvarsayımlarının sağlanıp sağlanmadığ 1 kontrol edilmelidir. $\mathrm{Bu}$ üç varsayımdan bir ya da birden fazlasının yerine getirilememesi durumunda ise dirençli tahmincilerden uygun olanı analizde kullanılacaktır.

Birinci varsayım olan homoskedasite varsayımı, hataların bağımsız ve özdeş dağılması olarak ifade edilebilir. Bu varsayım testi için Değiştirilmiş Wald Testi uygulanmıştır. Yapılan test sonucunda modelde homoskedasite varsayımının sağlanamadığı görülmüştür.

İkinci varsayım olan otokorelasyonsuzluk varsayımının sınanması adına araştırma modelinde Baltagi-Wu Yerel En İyi Değişmez testi uygulanmıştır. Yapılan test sonucunda modelde otokorelasyonluk varsayımının sağlanamadığı ve modelin otokorelasyon içerdiğ $i$ belirlenmiştir.

Son varsayım olan birimler arası korelasyonsuzluk (yatay kesit bağımsızlığı) varsayımının sınanması için Pesaran testi kullanılmıştır. Bu varsayımın sınanması için Pesaran testinin tercih edilmesinin sebebi analizde birim sayısının zaman sayısından daha fazla olmasıdır. Yapılan test sonucunda modelde birimler arası korelasyonsuzluk (yatay kesit bağımsızlığı) varsayımının sağlanamadığı görülmüştür.

Yapılan varsayım sinamalar1 sonras1, modelde heteroskedasite, otokorelasyon ve birimler arası korelasyon bulunduğu için uygun dirençli tahmincinin kullanılması gerekir. Model birim sabit etkiler modeli olduğu ve modeldehomoskedasite, otokorelasyon ve birimler arası korelasyon bulunduğu için model tahmincisi olarak Driscoll-Kraay dirençli tahmincinin kullanılması uygundur (Tatoğlu, 2016:287-297). 


\subsection{Analiz Bulguları}

Driscoll - Krayy tahmincisi ile yapılan analizde elde edilen sonuçlar Tablo 4'te gösterilmektedir.

Tablo 4. Driscoll - Kraay Tahmincisi Analiz Sonuçları

\begin{tabular}{|c|c|c|c|c|}
\hline Bağımsız Değişkenler & $\begin{array}{l}\text { Bağımlı } \\
\text { Değişken }\end{array}$ & $\mathbf{R}^{2}$ & $\mathbf{B}$ & $\begin{array}{l}\text { Anlamlılık } \\
\text { Düzeyi }\end{array}$ \\
\hline SÜRDÜRÜLEBİLİRLİK & \multirow{27}{*}{ ROA } & \multirow{27}{*}{0.3360} & 0.2777561 & $0.025^{* *}$ \\
\hline KALDIRAÇ & & & -0.0006751 & $\mathrm{AD}$ \\
\hline CARİ & & & 0.0009003 & $\mathrm{AD}$ \\
\hline BÜYÜME & & & -0.0387712 & $0.001 * * *$ \\
\hline RISK & & & 0.0000844 & $\mathrm{AD}$ \\
\hline ARGE & & & 0.0000000000475 & $\mathrm{AD}$ \\
\hline BÜYÜKLÜK & & & -0.0069485 & $\mathrm{AD}$ \\
\hline LAGROA & & & 0.4122769 & $0.003 * * *$ \\
\hline BIST & & & -0.000000997 & $0.005 * * *$ \\
\hline KARŞILAMA & & & -0.0049713 & $0.010^{* *}$ \\
\hline USD & & & 0.0419906 & $0.014^{* *}$ \\
\hline GSYİH & & & -0.0061366 & $\mathrm{AD}$ \\
\hline ENFLASYON & & & -0.0154698 & $0.099^{*}$ \\
\hline FAİZ & & & 0.0035653 & $0.012^{* *}$ \\
\hline DKALDIRAÇ & & & -0.0159421 & $\mathrm{AD}$ \\
\hline DCARİ & & & -0.0032611 & $\mathrm{AD}$ \\
\hline DBÜYÜME & & & 0.0785676 & $0.024^{* *}$ \\
\hline DRİSK & & & 0.0001751 & $\mathrm{AD}$ \\
\hline DARGE & & & 0.0000000000202 & $\mathrm{AD}$ \\
\hline DBÜYÜKLÜK & & & -0.0034103 & $\mathrm{AD}$ \\
\hline DLAGROA & & & 0.141095 & $\mathrm{AD}$ \\
\hline DBIST & & & -0.00000197 & $0.01 * *$ \\
\hline DKARŞILAMA & & & -0.0026607 & $\mathrm{AD}$ \\
\hline DUSD & & & 0.0092125 & $\mathrm{AD}$ \\
\hline DGSYİH & & & -0.5102379 & $\mathrm{AD}$ \\
\hline DENFLASYON & & & 0.0341235 & $0.011^{* *}$ \\
\hline DFAİZ & & & 0.0042615 & $\mathrm{AD}$ \\
\hline
\end{tabular}

Tablo 4 incelendiğinde, regresyon analizi sonucundaki $\mathrm{R}^{2}$ katsayısına göre, işletmelerin varlık kârlılıklarındaki değişimin \%33,60'ını analizde kullanılan değişkenler açıklamaktadır.

Tablo 4'te verilen analizler sonucu elde edilen bulgular şu şekilde özetlenebilir:

- Kurumsal sürdürülebilirliğin uygulamalarının firmaların finansal performansına anlamlı ve pozitif bir etkisinin olduğu görülmektedir $(\beta=0,2777561, p=0.025)$. Buna göre firmaların kurumsal sürdürülebilirlik uygulamalarına önem vermeleri finansal performanslarını arttırmalarını sağlayacaktır.

- Varlık büyüme oranı tek başına dikkate alındığında firmaların finansal performansina negatif ve istatistiksel olarak anlamlı bir etkisi varken $(\beta=-0,0387712$, 
$\mathrm{p}=0.001$ ), sadece işletmelerin kurumsal sürdürülebilirlik endeksine girdikleri dönemlere bakıldığında ise finansal performans üzerinde anlamlı ve pozitif bir etkisi olduğu bulunmuştur $(ß=0,0785676, p=0.024)$.

- $\quad$ Firmaların bir önceki dönem finansal performanslarının cari dönem finansal performanslarına anlamlı ve pozitif bir etkisinin olduğu bulunmuştur $(\beta=0,4122769$, $\mathrm{p}=0.003$ ).

- $\quad$ BIST 100 endeksinin işletmelerin finansal performanslarına anlamlı ve negatif bir etkisinin olduğu bulunmuştur $(\beta=-0.000000997, p=0.005)$. Sadece işletmelerin kurumsal sürdürülebilirlik endeksine girdikleri dönemlere bakıldığında da benzer şekilde BIST 100 endeksinin firmaların finansal performansına anlamlı ve negatif bir etkisinin olduğu bulunmuştur $(\beta=-0.00000197, \mathrm{p}=0.001)$.

- İhracatın ithalatı karşılama oranının işletmelerin finansal performanslarına anlamlı ve negatif bir etkisinin olduğu bulunmuştur $(\beta=-0.0049713, p=0.010)$.

- USD döviz kurunun işletmelerin finansal performanslarına anlamlı ve pozitif bir etkisinin olduğu bulunmuştur $(\beta=0,0419906, p=0.014)$.

- Enflasyon oranının işletmelerin finansal performanslarına anlamlı ve negatif bir etkisinin olduğu bulunmuştur $(\beta=-0,0154698, p=0.099)$. Ancak, sadece işletmelerin kurumsal sürdürülebilirlik endeksine girdikleri dönemlere bakıldığında ise enflasyon oranının finansal performansa anlamlı ve pozitif bir etkisinin olduğu bulunmuştur $(\beta=0,0341235$, $\mathrm{p}=0.011$ )

- Faiz oranlarının işletmelerin finansal performanslarına anlamlı ve pozitif bir etkisinin olduğu bulunmuştur $(\beta=0,0035653, p=0.012)$

\section{SONUÇ}

Çalışmada kurumsal sürdürülebilirliğin işletmelerin finansal performansı üzerinde bir etkisinin olup olmadığ 1 panel regresyon yöntemi ile test edilmiştir. Bu bağlamda kurumsal sürdürülebilirlik endeksinde yer alan banka dışı 35 işletmenin 2013-2016 yılları arasındaki 16 çeyrek dönemindeki finansal bilgilerinden yararlanılmıştır. Kullanılacak panel regresyon modelinin tespitine yönelik yapılan analizler sonucu veri setine uygun modelin sabit etkiler modeli olduğu belirlenmiştir. Varsayım testleri sonucunda da Driscoll-Kraay dirençli tahmincisinin kullanılmasının daha doğru olacağı tespit edilmiştir.

İşletmelerin finansal performansını ölçen bağımlı değişken olarak varlık kârlılı̆̆ (ROA) kullanılmıştır. Yapılan analizler sonucunda elde edilen en önemli bilgi işletmelerin kurumsal sürdürülebilirlik uygulamalarının finansal performanslarına anlamlı ve pozitif bir etkisinin olduğunun tespit edilmesidir. $\mathrm{Bu}$ bağlamda, finansal performanslarını ve kârlılıklarını arttırmak isteyen işletmelerin, yönetim kuruluna kurumsal sürdürülebilirlik yöneticisi atanması, kurumsal sosyal sorumluluk faaliyetlerine önem verilmesi, etik değerler ve yolsuzlukla mücadele gibi kurumsal yönetim ilkelerinin benimsenmesi; enerjinin verimli kullanılması, çevresel dengenin ve doğal kaynakların korunmasına yönelik adımların atılması gibi kurumsal sürdürülebilirlik uygulamalarına yönelmesinin faydalı bir adım olacağ düşünülmektedir.

Bunun yanında, firmaların bir önceki dönem finansal performansının, USD döviz kurunun ve faiz oranının firmaların finansal performanslarına pozitif ve anlamlı bir etkisinin olduğu sonucuna ulaşılmıştır. Ayrıca, varlık büyüme oranı, BIST 100 endeksi, ihracatın 
ithalatı karşılama oranı ve enflasyon oranının firmaların finansal performansına negatif ve anlamlı bir etkisinin olduğu bulunmuştur.

Gelecek dönemlerde kurumsal sürdürülebilirlik endeksine giren işletme sayısının ve analize dâhil edilecek dönem sayısının artmasıyla kurumsal sürdürülebilirlik uygulamalarının işletmelerin finansal performasına etkisi daha zengin analizlerle değerlendirilebilecektir.

\section{KAYNAKLAR}

Aggarwal, Priyanka (2013), "Impact of Sustainability Performance of Company on its Financial Performance: A Study of Listed Indian Companies", Global Journal of Management and Business Research, 13(11), pp.60-70.

Altınay, Ayşenur - Kaki, Barış - Kestane, Ali - Soba, Mustafa - Dinçer, Ömer - Şık, Eser (2017), "Sürdürülebilirlik Endeksinin Bankacılık Sektörü Hisse Senedi Değerlerine Etkileri, BIST Sürdürülebilirlik Endeksi Üzerine Bir İnceleme”, Sosyal Ekonomik Araştırmalar Dergisi, 17(34), ss.208-229.

Charlo, Maria - Moya, Ismael - Muñoz, Ana (2015), "Sustainable Development andCorporate Financial Performance: A StudyBased on the FTSE4Good IBEX Index", Business Strategyandthe Environment, 24(4), pp.277-288.

Collison, David - Cobb, George - Power, David - Stevenson, Lorna (2008), "The Financial Performance of the Indices", CorporateSocialResponsibilityandEnvironmental Management, 15(1), pp.14-28.

Çıtak, Levent - Ersoy, Ersan (2016), "İşletmelerin BIST Sürdürülebilirlik Endeksine Alınmasına Yatırımcı Tepkisi: Olay Çalışması ve Ortalama Testleri ile Bir Analiz”, Uluslararası Alanya Fakültesi işletme Dergisi, 8(1), ss.43-57.

Lo, ShihFang - Sheu, Her-Jiun (2007), "Is CorporateSustainability A Value-IncreasingStrategyfor Business?", CorporateGovernance: An International Review, 15(2), pp.345-358.

Lopez, Victoria - Garcia, Arminda - Rodriguez, Lazaro (2007), "Sustainable Development andCorporatePerformance: A StudyBased on the Dow JonesSustainability Index", Journal of Business Ethics, 75(3), pp.285-300.

Marti, CarmenPillar - Rovira Val, Rosa - Drescher, Lisa G. (2015), "AreFirmsThatContributetoSustainable Development BetterFinancially?", CorporateSocialResponsibilityandEnvironmental Management, 22(5), pp.305-319.

Nunes, Katia R. A. - Valle, A.R. - Peixoto, J. A. A. - Schebek, L. (2010) "Automotive IndustrySustainabilityReports: A Comparison of BrazilianandGermanFactories”, In VI CongressoNacional de Excelencia em Gestao, pp.1-24.

Önder, Şerife (2017), “İşletme Karlılı̆̆ına Kurumsal Sürdürülebilirliğin Etkisi: BIST'te Bir Uygulama", Muhasebe Bilim Dünyası Dergisi, 19(4), ss.937-956. 
Park, Hun Myoung (2011), "Practical Guidelines to Panel Data Modeling: A Step By Step Analysis Using Stata", Uluslarası Japonya Üniversitesi Uluslararası İlişkiler Enstitüsü Çalışma Kağıdı, pp.1-52

PWC, PriceWaterhouseCoopers, (2011), "Türk İş Dünyası'nda Sürdürülebilirlik Uygulamalar1 Raporu", (https://www.pwc.com.tr/tr/publications/arastirmalar/pdf/pwc_SÜRDÜRÜLEBİLİRLİ K_raporu-2012.pdf, (05.03.2018).

Reddy, Krishna - Gordon, Lucus (2010), “TheEffect of SustainabilityReporting on Financial Performance: An EmpiricalStudy Using ListedCompanies", Journal of Asia Entrepreneurship and Sustainability, 6(2), pp.19-42.

Russo, Angeloantonio - Mariani, Massimo (2013), "Drawbacks of a DelistingFrom a Sustainability Index: An Empirical Analysis", International Journal of Business Administration, 4(6), pp.29-40.

Skare, MarinkoandGolja, Tea (2012), "Corporate Social Responsibility and Corporate Financial Performance-Is There a Link?”, EconomicResearch, (1), pp.215-242.

Tatoğlu, Ferda Yerdelen (2016), Panel Veri Ekonometrisi, 3. Bask1, Beta Yayınevi, İstanbul.

Tokgöz, Nuray - Önce, Saime (2009), "Işletme Sürdürülebilirliği: Geleneksel Yönetim Anlayışına Alternatif”, Afyon Kocatepe Üniversitesi İİBF Dergisi, 11(1), ss.249-275.

WCED, Word Commission on Environment and Development, (1987), "OurCommonFuture", www.exteriores.gob.es/Portal/es/.../Informe\%20Brundtland\%20(En\%20inglés).pdf, $(07.02 .2018)$

Wiengarten, Frank - Lo, Chris K. - Lam, Jessie. Y. (2017), "How DoesSustainabilityLeadershipAffectFirmPerformance?

TheChoicesAssociatedwithAppointing a Chiefofficer of Corporate Social Responsibility", Journal of Business Ethics, 140(3), pp.477-493. 